\title{
Introduction of Branching Degrees of Octane Isomers
}

\author{
Anton Perdih \\ Faculty of Chemistry and Chemical Technology, University of Ljubljana (retired) Večna pot 113, \\ 1000 Ljubljana, Slovenia \\ * Corresponding author: E-mail: a.perdih@gmail.com
}

Received: 17-02-2016

\begin{abstract}
The concept of branching degrees is introduced. In the case of octane isomers it is derived from the values of a set of their physicochemical properties, calculating for each isomer the average of the normalized values and these averages are defined as branching degrees of octane isomers. The sequence of these branching degrees of octane isomers does not differ much from the »regular « one defined earlier. 2,2-Dimethylhexane appears to be less branched than 3,4-dimethylhexane and 3-ethyl, 2-methylpentane, whereas 2,3,4-trimethylpentane appears to be less branched than 3-ethyl, 3methylpentane. While the increasing number of branches gives rise to increasing branching degrees, the peripheral position of branches and the separation between branches decreases the value of the branching degree. The central position of branches increases it. A bigger branch increases it more than a smaller one. The quantification of these structural features and their correlations with few indices is given as well.
\end{abstract}

Keywords: Branching degree, Distance number, Number of branches, Octanes, Peripheral number, Size of the largest branch

\section{Introduction}

Branching of alkanes is a concept to which much attention had been paid. For example, Bonchev and Trinajstic $^{1}$ formulated several general rules for branching based on Wiener ${ }^{2}$ index that were improved later. ${ }^{3}$ Randicic reminded that branching was in fact attempted to be defined using few topological indices, either the Wiener index ${ }^{2}$ or the largest eigenvalue of the adjacency matrix ${ }^{5,6}$ and he provided the largest eigenvalue of the path matrix as a new basis for the definition of branching. ${ }^{4}$ Randić and Wilkins ${ }^{7}$ followed with the ordering of structures based on path indices. Later ${ }^{8}$ were presented »regular «, in part intuitively derived sequences of octane isomers of increasing branching, one of them being Oct $<2 \mathrm{M} 7<3 \mathrm{M} 7<4 \mathrm{M} 7<3 \mathrm{Et} 6$ $<25 \mathrm{M} 6<24 \mathrm{M} 6<23 \mathrm{M} 6<34 \mathrm{M} 6<3 \mathrm{Et} 2 \mathrm{M} 5<22 \mathrm{M} 6<$ $33 \mathrm{M} 6<3$ Et3M5 < 234M5 < 224M5 < 223M5 < 233M5 < $2233 \mathrm{M} 4$, as well as the indices derived from a simplified version of the Universal matrix giving rise to such $»$ regular « sequences of octane isomers. Such a »regular « sequence is observed among some of the indices ${ }^{9-12} \mathrm{~V}(\mathrm{a}, \mathrm{b}$, $c) \equiv \mathrm{V}_{w m}(a, b, c)$ and $\mathrm{V}_{\mathrm{L}}(\mathrm{a}, \mathrm{b}, \mathrm{c})$ as well as among some of the vertex degree weighted path one indices.

Randić and Wilkins ${ }^{7}$ introduced and discussed the significance of the results of ordering of alkane isomers based on paths of length two $\left(p_{2}\right)$ and paths of length three $\left(p_{3}\right)$ as well as their conceptual value. The degeneration of $\mathrm{p}_{2}$ and $\mathrm{p}_{3}$, as well as their integer values enabled Randić and Wilkins ${ }^{7}$ to form rectangular grid graphs in form of coordinate systems similar to Mendeleev's periodic system of elements.

In present paper there is made an attempt to quantify the positions of octanes in the »regular « sequences of octane isomers based on some physicochemical properties (PCP) of them, the sequences of which are the closest to the »regular « sequence. Octanes were chosen since this is the largest group of alkane isomers for which a number of data is known for all or most of isomers.

\section{Notation and Physicochemical Properties of Octane Isomers}

Notations and physicochemical properties of octane isomers were presented in a previous paper. ${ }^{9}$

\section{Derivation of Sequences}

The software for statistics calculations included in the program package MS Excel was used. 
The physicochemical properties of octane isomers were chosen in such a way that between their values and the »regular « equidistant sequence of octane isomers of increasing branching being ${ }^{8}$ Oct $<2 \mathrm{M} 7<3 \mathrm{M} 7<4 \mathrm{M} 7<$ 3 Et6 $<25 \mathrm{M} 6<24 \mathrm{M} 6<23 \mathrm{M} 6<34 \mathrm{M} 6<3 \mathrm{Et} 2 \mathrm{M} 5<22 \mathrm{M} 6$ $<33$ M6 < 3Et3M5 < 234M5 < 224M5 < 223M5 < 233M5 $<2233 \mathrm{M} 4$, to which the integer values of 1 to 18 , respectively, were ascribed, the correlation coefficient was $|R|>$ 0.90. This criterion was fulfilled for the following physicochemical properties of octanes: Octane Numbers (MON, BON, RON), reduced boiling point (BP/Tc), the van der Waals parameters $a_{0}$ and $b_{0}$ represented here by the ratios $\mathrm{Tc} / \mathrm{Pc}$ and $\mathrm{Tc}^{2} / \mathrm{Pc}$, respectively, the Antoine constant C, the Pitzer's acentric factor $\omega$, and the entropy S. Then, the values of these physicochemical properties were normalized relatively to the number of branches in the octane isomers in such a way that the normalized values in the case of $n$-octane (Oct) were equal to 0 (zero), and in the case of 2,2,3,3-tetramethylbutane (2233M4) were equal to 4 . In the case of Octane Numbers, for which the experimental values for 2,2,3,3-tetramethylbutane were not known, the normalized values for 2,3,3-trimethylpentane were ascribed to be equal to 3 . After normalization of the values of these physicochemical properties, the average of the normalized values for each isomer was calculated and these averages are defined as branching degrees of octane isomers.

The peripheral number $\mathrm{N}_{\text {per }}$ is defined as $\Sigma \mathrm{d}_{\text {sy }}$, where $d_{s y}$ is the distance of a branch from the axis of symmetry of the main chain of the molecular graph. The distance number $\mathrm{N}_{\mathrm{d}}$ is defined as the distance between two branches. The size of the largest branch $\mathrm{L}_{b r}$ is equal to the number of vertices in the branch.

\section{Results and Discussion}

The resulting branching degrees of octane isomers are presented for the »regular « sequence of octane isomers in Figure 1, whereas the sequence of octanes using these branching degrees of octane isomers together with their values is presented in Figure 2 as well as in Table 1.

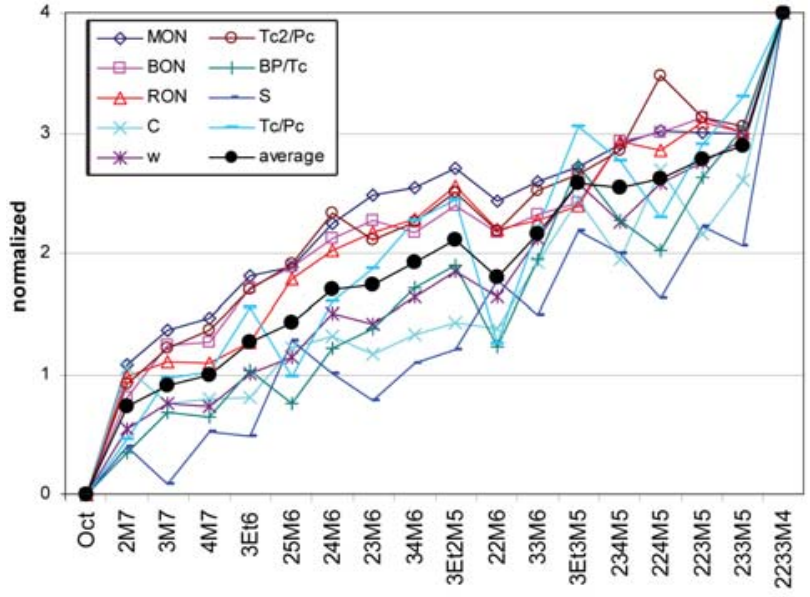

Figure 1. Normalized values of physicochemical properties of octane isomers and their average.

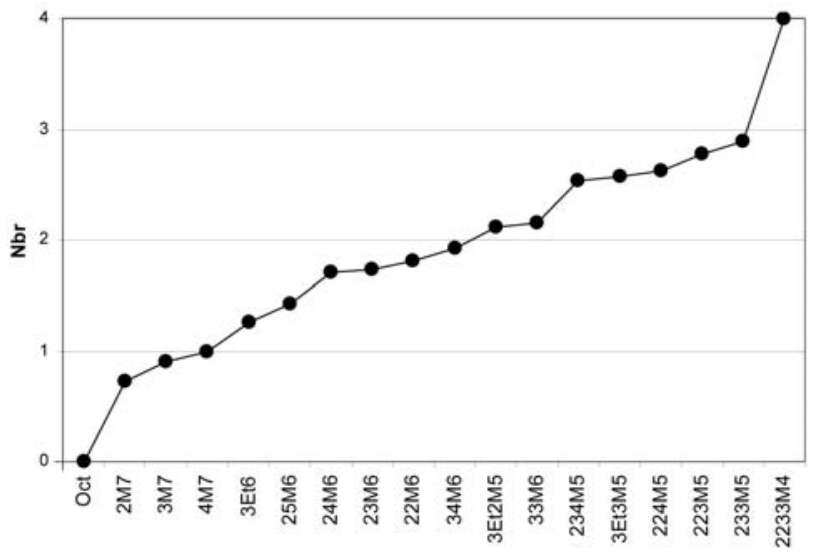

Figure 2. Sequence of octane isomers of increasing branching based on data of the branching degrees derived from their physicochemical properties.

The sequence of branching degrees of octane isomers derived using the data for the physicochemical properties of octanes: MON, BON, RON, BP/Tc, Tc/Pc, $\mathrm{Tc}^{2} / \mathrm{Pc}, \mathrm{C}, \omega$, and $\mathrm{S}$, which is Oct $<2 \mathrm{M} 7<3 \mathrm{M} 7<4 \mathrm{M} 7<$ 3 Et6 $<25 \mathrm{M} 6<24 \mathrm{M} 6<23 \mathrm{M} 6<22 \mathrm{M} 6<34 \mathrm{M} 6<3 \mathrm{Et} 2 \mathrm{M} 5$

Table 1. Branching degrees of octane isomers derived from the normalized data of the physicochemical properties of octanes as well as the measures of structural

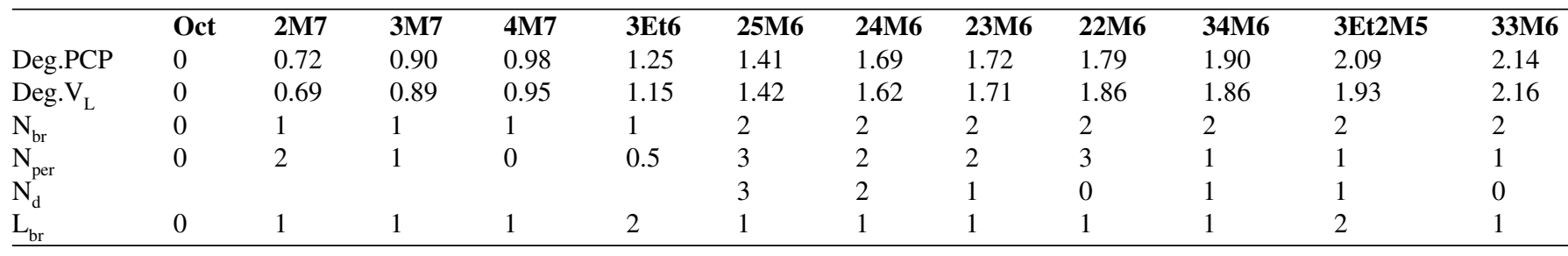

Deg.PCP - Branching degrees derived from the physicochemical properties of octanes: MON, BON, RON, BP/Tc, Tc/Pc, Tc $2 / \mathrm{Pc}, \mathrm{C}, \omega$, and $\mathrm{S}$ as the average of the Deg. $\mathrm{V}_{\mathrm{L}}-$ Branching degrees derived from the values of index $\mathrm{V}_{\mathrm{L}}(-0.126,-0.139,-0.27)$.

$\mathrm{N}_{\mathrm{br}}$ - number of branches, $\mathrm{N}_{\mathrm{per}}$ - peripheral number, $\mathrm{N}_{\mathrm{d}}-$ distance number, $\mathrm{L}_{\mathrm{br}}$ - the size of the largest branch. 
Table 2. Correlation of physicochemical properties of octanes with the branching degrees presented in Table 1 ( $R$ br. deg.) sorted by $|R|$, with the »regular « equidistant sequence of octane isomers $(R »$ reg.«), with the number of branches $\left(R \mathrm{~N}_{\mathrm{br}}\right)$, with the peripheral number $\left(R \mathrm{~N}_{\text {per }}\right)$, with the distance number $\left(R \mathrm{~N}_{\mathrm{d}}\right)$ as well as with the size of the largest branch $\left(R \mathrm{~L}_{\mathrm{br}}\right)$.

\begin{tabular}{|c|c|c|c|c|c|c|}
\hline$\overline{\mathbf{P C P}}$ & $R$ br. deg. & $R » \mathrm{reg}_{\ll}$ & $R \mathbf{N}_{\mathrm{br}}$ & $\boldsymbol{R} \mathbf{N}_{\text {per }}$ & $R \mathbf{N}_{\mathrm{d}}$ & $R \mathrm{~L}_{\mathrm{br}}$ \\
\hline br. deg. & 1 & 0.961 & 0.959 & 0.300 & -0.237 & 0.283 \\
\hline$\omega$ & -0.993 & -0.969 & -0.941 & -0.264 & 0.226 & -0.244 \\
\hline RON & 0.979 & 0.943 & 0.974 & 0.408 & -0.357 & 0.333 \\
\hline BON & 0.976 & 0.934 & 0.965 & 0.395 & -0.241 & 0.373 \\
\hline $\mathrm{BP} / \mathrm{Tc}$ & -0.976 & -0.943 & -0.893 & -0.114 & 0.356 & -0.287 \\
\hline $\mathrm{Tc}^{2} / \mathrm{Pc}$ & -0.976 & -0.944 & -0.964 & -0.402 & 0.111 & -0.311 \\
\hline MON & 0.969 & 0.911 & 0.932 & 0.357 & -0.485 & 0.445 \\
\hline $\mathrm{Tc} / \mathrm{Pc}$ & -0.963 & -0.923 & -0.878 & -0.073 & 0.433 & -0.374 \\
\hline $\mathrm{C}$ & 0.957 & 0.929 & 0.914 & 0.306 & -0.085 & 0.196 \\
\hline $\mathrm{S}$ & -0.941 & -0.938 & -0.902 & -0.324 & 0.132 & -0.153 \\
\hline$\overline{\mathrm{R}^{2}}$ & -0.874 & -0.865 & -0.903 & -0.393 & 0.111 & -0.320 \\
\hline$\Delta \mathrm{Hv}$ & -0.850 & -0.865 & -0.893 & -0.628 & -0.298 & -0.104 \\
\hline Pc & 0.846 & 0.801 & 0.714 & -0.189 & -0.519 & 0.368 \\
\hline A & -0.659 & -0.768 & -0.726 & -0.581 & -0.258 & -0.126 \\
\hline $\mathrm{Vc}$ & -0.622 & -0.629 & -0.498 & 0.156 & 0.512 & -0.552 \\
\hline BP & -0.619 & -0.619 & -0.732 & -0.808 & -0.500 & -0.013 \\
\hline$\Delta \mathrm{Hf}^{\circ} \mathrm{g}$ & 0.617 & 0.611 & 0.718 & 0.792 & 0.397 & -0.124 \\
\hline $\mathrm{dc}$ & 0.609 & 0.620 & 0.485 & -0.159 & -0.499 & 0.541 \\
\hline$\alpha c$ & -0.594 & -0.695 & -0.603 & -0.192 & 0.166 & -0.317 \\
\hline $\log \mathrm{VP}$ & 0.586 & 0.556 & 0.668 & 0.587 & 0.508 & 0.038 \\
\hline MR & -0.585 & -0.507 & -0.540 & 0.312 & 0.506 & -0.398 \\
\hline $\mathrm{Zc}$ & 0.582 & 0.515 & 0.611 & 0.296 & 0.072 & -0.153 \\
\hline $\mathrm{d}$ & 0.495 & 0.447 & 0.570 & -0.084 & -0.257 & 0.114 \\
\hline $\mathrm{Vm}$ & -0.489 & -0.441 & -0.569 & 0.116 & 0.290 & -0.137 \\
\hline $\mathrm{n}_{\mathrm{D}}$ & 0.429 & 0.397 & 0.548 & -0.046 & -0.214 & 0.066 \\
\hline B & -0.251 & -0.420 & -0.411 & -0.801 & -0.530 & 0.054 \\
\hline $\mathrm{Tc}$ & 0.152 & 0.123 & -0.035 & -0.753 & -0.606 & 0.223 \\
\hline ST & -0.137 & -0.161 & -0.342 & -0.858 & -0.600 & 0.228 \\
\hline CED & 0.101 & -0.070 & -0.036 & -0.522 & -0.403 & 0.052 \\
\hline Sol.par. & 0.091 & -0.062 & -0.046 & -0.530 & -0.409 & 0.054 \\
\hline
\end{tabular}

Meaning of acronyms for physicochemical properties of octanes:

$\omega$ : Pitzer's acentric factor, BON, MON, RON: Octane Numbers, $\mathrm{Tc}^{2} / \mathrm{Pc}$ : represents the van der Waals parameter $\mathrm{b}_{0}$, BP/Tc: reduced boiling point, Tc/Pc: represents the van der Waals parameter $\mathrm{a}_{0}$, $\mathrm{S}$ : entropy, $\mathrm{A}, \mathrm{B}, \mathrm{C}$ : Antoine constants, $\Delta \mathrm{Hv}$ : enthalpy of vaporisation, $\mathrm{R}^{2}$ : quadratic mean radius, $\mathrm{Pc}$ : critical pressure, $\Delta \mathrm{Hf}^{\circ} \mathrm{g}$ : standard enthalpy of formation for the ideal gas, BP: boiling point, logVP: vapour pressure, Zc, $\alpha c, V c, d c$, Tc: critical data, MR: molar refraction, d: density, Vm: liquid molar volume, $\mathrm{n}_{\mathrm{D}}$ : refractive index, $\mathrm{ST}$ : surface tension, CED: cohesive energy density, Sol.par.: solubility parameter.

$<33 \mathrm{M} 6<234 \mathrm{M} 5<3$ Et3M5 < 224M5 < 223M5 < 233M5 $<2233 \mathrm{M} 4$, does not differ much from the $»$ regular $^{8}{ }^{8}$ one, which is Oct $<2 \mathrm{M} 7<3 \mathrm{M} 7<4 \mathrm{M} 7<3 \mathrm{Et} 6<25 \mathrm{M} 6<$

features.

$\begin{array}{llllll}\text { 234M5 } & \text { 3Et3M5 } & \text { 224M5 } & \text { 223M5 } & \text { 233M5 } & \text { 2233M4 } \\ 2.52 & 2.56 & 2.59 & 2.75 & 2.87 & 4 \\ 2.51 & 2.40 & 2.64 & 2.90 & 2.99 & 4 \\ 3 & 2 & 3 & 3 & 3 & 4 \\ 2 & 0 & 3 & 2 & 1 & 2 \\ 1 & 0 & 2 & 1 & 1 & 1 \\ 1 & 2 & 1 & 1 & 1 & 1\end{array}$

normalized values.
$24 \mathrm{M} 6<23 \mathrm{M} 6<34 \mathrm{M} 6<3 \mathrm{Et} 2 \mathrm{M} 5<22 \mathrm{M} 6<33 \mathrm{M} 6<$ 3Et3M5 < 234M5 < 224M5 < 223M5 < 233M5 < 2233M4. They correlate to one another to $R=0.967$.

Only the isomer 22M6 appears to be less branched than 34M6 and 3Et2M5, as well as 234M5 appears to be less branched than 3Et3M5.

The sequence of isomers of increasing branching, as well as the values of branching degrees based on physicochemical properties of octanes, confirm the previous conclusions based on topological indices ${ }^{1,3,4}$ that the most important structural feature regarding branching is the number of branches. In the case of the branching degrees of octane isomers derived here, it is overwhelmed only in the case of 234M5 < 3Et3M5. The next important previously ${ }^{1,3,4}$ known structural feature is the position of branches. The more peripherally positioned the branch the less 
branched appears the octane. And vice versa, the more centrally is positioned the branch the more branched appears the octane, as for example in $2 \mathrm{M} 7<3 \mathrm{M} 7<4 \mathrm{M} 7$, in $25 \mathrm{M} 6<24 \mathrm{M} 6<23 \mathrm{M} 6<34 \mathrm{M} 6$, as well as in 224M5 < $223 \mathrm{M} 5<233 \mathrm{M} 5$. The sequence of $25 \mathrm{M} 6<24 \mathrm{M} 6<23 \mathrm{M} 6$ $<22 \mathrm{M} 6$ illustrates that the greater distance between branches being in this case $3>2>1>0$ gives rise to a lesser branching degree. The sequences 4M7 < 3Et6, 23M6 $<3$ Et2M5, and 33M6 < 3Et3M5 illustrate that the bigger is a centrally positioned branch the more branched appears the octane. Only in the case of 234M5 < 3Et3M5 the combined central position of two branches, one small and one bigger, and the zero distance between them slightly overwhelm the influence of the number of branches being one distance unit apart, where two of the three are peripheral.

Thus, the peripheral position of branches decreases the value of branching degree presented by the number of branches, whereas the central position of branches increases it. The separation between branches decreases it as well. A bigger branch increases it more than a smaller one.

The sequences of values of particular physicochemical properties of octanes deviate more or less from the sequence of branching degrees of octane isomers derived here. Whereas in the »regular « sequence of octane isomers there prevails the influence of the number of branches over the joint influence of the position of branches, the separation between them, and the type of branches, in the sequence of the branching degrees of octane isomers derived here, there is one exception to this rule. In the real values of physicochemical properties of octanes, the lower is the value of $|R|$ br. deg. presented in Table 2 the less influence on their values has the number of branches and the more the other structural features.

One of the most illustrative examples in this respect is Tc, Table 2, correlating to the branching degree to $R=$ 0.152 , to the $»$ regular « sequence of octane isomers to $R=$ 0.123 , and to the number of branches $\mathrm{N}_{\mathrm{br}}$ to $R=-0.035$. In the case of $\mathrm{Tc}$, the influence of the position of branches appears to be deciding. The peripherally positioned branches give rise to lower values of Tc, whereas the centrally positioned branches give rise to higher values of Tc. As a consequence, $\mathrm{Tc}$ correlates to the peripheral number $\mathrm{N}_{\text {per }}$ to $R=-0.753$, whereas to the distance number $\mathrm{N}_{\mathrm{d}}$ to $R=$ -0.606 and to the size of the largest branch $\mathrm{L}_{\mathrm{br}}$ to $R=$ 0.223 .

This is in contrast to $\mathrm{Tc}^{2} / \mathrm{Pc}$, correlating to the branching degree to $R=-0.976$, to the »regular « sequence of octane isomers to $R=-0.944$, whereas it correlates to $\mathrm{N}_{\mathrm{br}}$ to $R=-0.964$, to $\mathrm{N}_{\text {per }}$ to $R=-0.402$, to $\mathrm{L}_{\mathrm{br}}$ to $R=$ -0.311 , and to $\mathrm{N}_{\mathrm{d}}$ to $R=0.111$ only.

Other interesting example, where the correlations are low, are the critical properties $\mathrm{Vc}$ and dc where $|R| \mathrm{L}_{\mathrm{br}}$ $>|R| \mathrm{N}_{\mathrm{d}}>|R| \mathrm{N}_{\mathrm{br}}>|R| \mathrm{N}_{\mathrm{per}}$, indicating that the size of the branch is the most important at these physicochemical properties. Another interesting example, where the corre- lations are very low, are the cohesive energy density (CED) and the solubility parameter (Sol. par.), where $|R|$ $\mathrm{N}_{\text {per }}>|R| \mathrm{N}_{\mathrm{d}}>>|R| \mathrm{L}_{\mathrm{br}}>|R| \mathrm{N}_{\mathrm{br}}$. Other comparisons can be made as well, using data in Table 2.

The measures of structural features presented in Table 1 correlate with one another to a low degree. This is presented in Table 3.

Table 3. Correlations $(R)$ between the measures of the structural features presented in Table 1.

\begin{tabular}{lllcc}
\hline & $\mathrm{N}_{\mathrm{br}}$ & $\mathrm{N}_{\text {per }}$ & $\mathrm{N}_{\mathrm{d}}$ & $\mathrm{L}_{\mathrm{br}}$ \\
\hline $\mathrm{N}_{\mathrm{br}}$ & 1 & & & \\
$\mathrm{~N}_{\text {per }}$ & 0.512 & 1 & & \\
$\mathrm{~N}_{\mathrm{d}}$ & 0.079 & 0.545 & 1 & \\
$\mathrm{~L}_{\mathrm{br}}$ & 0.129 & -0.179 & -0.297 & 1 \\
\hline
\end{tabular}

Branching degrees of octane isomers were not intended to represent a new index but to be only a quantitative illustration of the degree of branching of octane isomers as it is felt by a group of their physicochemical properties. Previous ${ }^{12}$ results have shown that topological indices, which describe the »regular « sequence of octane isomers, are not good indices for physicochemical properties of octane isomers. This is reflected in Table 2 also for the branching degrees of octane isomers, where only the Pitzer's acentric factor $\omega$ exceeds the lower limit of usefulness of $R=0.99 .{ }^{13}$ However, the comparison of their goodness with that of a previously published index group, namely $p_{2} / w_{2}$ and $p_{3} / w_{3},{ }^{14}$ where only one physicochemical property of octane isomers, namely MR, slightly exceeds the limit value $\mathrm{e}^{13}$ of $R=0.99$, indicates the values of $R$ of similar level. Indices giving rise to better goodness regarding the physicochemical properties of octane isomers were presented elsewhere. ${ }^{9,12}$

Sequences of structural features $\mathrm{N}_{\mathrm{br}}, \mathrm{N}_{\mathrm{per}}, \mathrm{N}_{\mathrm{d}}$ and $\mathrm{L}_{\mathrm{br}}$ according to the sequence of the absolute values of their correlation coefficients $|R|$ ( $R$ given in parentheses) are at the branching degree and some indices as follows:

Branching degree: ${ }^{\text {here }} \quad \mathrm{N}_{\mathrm{br}}(0.959)>\mathrm{N}_{\mathrm{per}}(0.300)>$

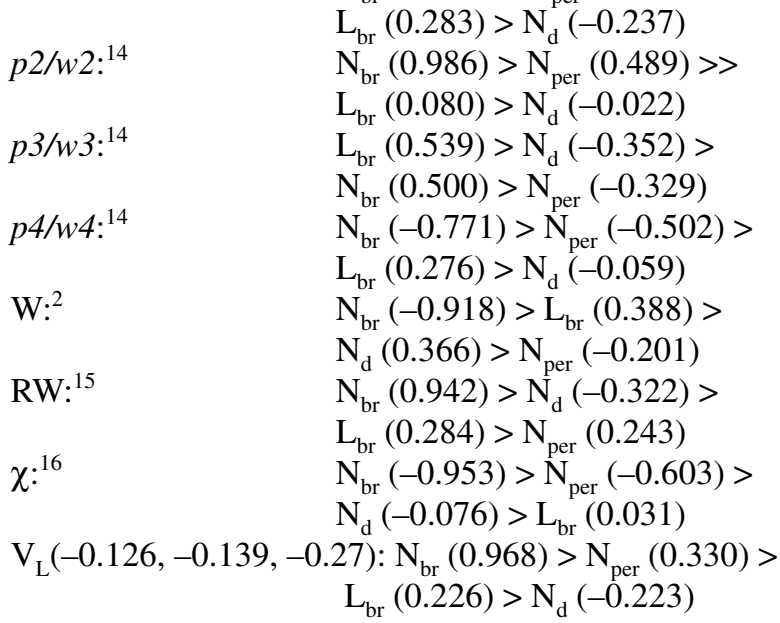


Interesting is the remarkable correlation $(R=0.991)$ of RW with the degree of branching of octanes presented here. However, due to a higher influence of the distance between branches, $\mathrm{N}_{\mathrm{d}}$, the RW differs from the degree of branching of octanes in partial sequences $25 \mathrm{M} 6<3 \mathrm{Et} 6$ and $224 \mathrm{M} 5<234 \mathrm{M} 5$. While $\mathrm{RW}=\mathrm{V}_{\mathrm{L}}(0,0,-1)$, cf. ref. ${ }^{9,10}$, the index $\mathrm{V}_{\mathrm{L}}(-0.126,-0.139,-0.27)$ correlates to the branching degree of octanes derived here to $R=0.996$ and gives the sequence of octane isomers Oct $<2 \mathrm{M} 7<$ $3 \mathrm{M} 7<4 \mathrm{M} 7<3 \mathrm{Et} 6<25 \mathrm{M} 6<24 \mathrm{M} 6<23 \mathrm{M} 6<22 \mathrm{M} 6<$ $34 \mathrm{M} 6<3$ Et2M5 < 33M6 < 3Et3M5 < 234M5 < 224M5 < $223 \mathrm{M} 5<233 \mathrm{M} 5<2233 \mathrm{M} 4$, which is regarding the intuition better than that of the degree of branching of octanes derived above since in it there exists the sequence 3Et3M5 $<234 \mathrm{M} 5$ and not 234M5 < 3Et3M5.

Different indices depend thus differently on the structural features of octanes, therefore the grouping of physicochemical properties of octanes based on correlations with them ${ }^{14}$ varies with their properties and is not necessarily equal to that derived by the intercorrelation of physicochemical properties of octanes themselves. ${ }^{9}$

The results presented in Table 2 indicate also some classification of physicochemical properties of octanes. It can be compared to the classification based on the indices $p_{i} / w_{i},{ }^{14}$ as well as to that based on correlations between the physicochemical properties of octanes. ${ }^{9}$

\section{References}

1. D. Bonchev, N. Trinajstić, J. Chem. Phys. 1977, 67, 45174533. http://dx.doi.org/10.1063/1.434593

2. H. Wiener, J. Am. Chem. Soc. 1947, 69, 17-20. http://dx.doi.org/10.1021/ja01193a005

3. D. Bonchev, J. Molec. Struct. (Theochem), 1995, 336, 137156. http://dx.doi.org/10.1016/0166-1280(94)04081-3

4. M. Randić, Acta Chim. Slov. 1997, 44, 57-77.

5. L. Lovasz, J. Pelikan, Period Math Hung. 1973, 3, 175-182. http://dx.doi.org/10.1007/BF02018473

6. D. M. Cvetković, I. Gutman, Croat. Chem. Acta, 1977, 49, 115-121.

7. M. Randić, C. L. Wilkins, J. Phys. Chem. 1979, 83, 15251540. http://dx.doi.org/10.1021/j100474a032

8. A. Perdih, Indian J. Chem, 2003, 42A, 1246-1257.

9. A. Perdih, Acta Chim. Slov. 2015, 62, 879-888. http://dx.doi.org/10.17344/acsi.2015.1607

10. A. Perdih, B. Perdih, Acta Chim. Slov. 2004, 51, 598-609.

11. A. Perdih, Acta Chim. Slov. 2015, 62, 385-388. http://dx.doi.org/10.17344/acsi.2014.1164

12. A. Perdih, Acta Chim. Slov. 2016, 63, 88-96. http://dx.doi.org/10.17344/acsi.2015.1975

13. Z. Mihalić, N. Trinajstić, J. Chem. Educ. 1992, 69, 701-712. http://dx.doi.org/10.1021/ed069p701

14. M. Randić, J. Chem. Inf. Comput. Sci. 2001, 41, 607-613. http://dx.doi.org/10.1021/ci0001031

15. M.V. Diudea, J. Chem. Inf. Comput. Sci. 1997, 37, 292-299. http://dx.doi.org/10.1021/ci960037w

16. M. Randić, J. Am. Chem. Soc. 1975, 97, 6609-6615. http://dx.doi.org/10.1021/ja00856a001

\section{Povzetek}

Uveden je pojem stopnja razvejanosti. Vrednosti stopnje razvejanosti so izračunane iz normaliziranih vrednosti skupine fizikokemijskih lastnosti oktanov. Zaporedje teh vrednosti ne odstopa veliko od »regularnega« zaporedja določenega prej. Izračunane stopnje razvejanosti oktanov kažejo, da je 2,2-dimetilheksan manj razvejan kot sta 3,4-dimetilheksan in 3-etil,2-metilpentan, medtem ko je 2,3,4-trimetilpentan manj razvejan kot 3-etil,3-metilpentan. Medtem ko večanje števila vej povečuje vrednost stopnje razvejanosti, jo robni položaj vej in razdalja med vejami zmanjšujeta. Sredinski položaj vej jo povečuje. Večje veje jo povečajo bolj kot majhne. Podano je tudi vrednotenje teh strukturnih značilnosti in njihove korelacije z nekaterimi indeksi. 
